\title{
ÉXITO Y OCASO DE UNA SAGA DE NEGOCIANTES CATALANES EN GALICIA: LA CASA DE COMERCIO FRANCISCO FERRER Y ALBÀ (1750-1860) ${ }^{1}$
}

\author{
MARGARITA VILAR RODRÍGUEZ \\ Universidad de A Coruña
}

\begin{abstract}
Resumen
Este artículo trata de revisar el fenómeno social y económico que supuso la llegada de negociantes catalanes a Galicia en el siglo XVIII. Este tema ha sido tratado ampliamente por la historiografía gallega bien desde una perspectiva global o bien a través de apellidos empresariales ilustres, muchos de los cuales han sobrevivido hasta nuestros días. Sin embargo, no podemos olvidar que muchas de las familias catalanas que llegaron a tierras gallegas eran de origen más modesto y que el éxito no siempre les acompañó en sus negocios, tal y como le ocurrió a la Casa de Comercio Francisco Ferrer y Albà. La historia de esta saga desde su asentamiento hasta su declive nos ofrece una nueva perspectiva de análisis en la que nos encontramos con una compañía familiar, fundada por fomentadores catalanes, que no pudo o no supo sobrevivir a los agitados años que vivió España entre 1750 y 1860.
\end{abstract}

\section{Palabras clave}

Historia empresarial, economía gallega, fomentadores catalanes, siglos XVIII y XIX.

\begin{abstract}
This article tries to review the social and economic phenomenon that meant the arrival of Catalonian businessmen to Galicia in the eighteenth century. This line of research has been extensively studied by the Galician historiography either from a global point of view or through famous business families, most of them have survived till nowadays. However, we can not forget that many of the Catalonian families that arrived at Galician lands had a humbler origin and they were not always successful in business. The Casa de Comercio Francisco Ferrer Albà is an example of this. The history of this saga from its settlement to its decline offers a new perspective of analysis in that we can find a family company, founded by Catalonian promoters, which could not survive the disturbed years that Spain lived from 1750 to 1860 .
\end{abstract}

\section{Key Words}

Business history, Galician economy, salted fish, Catalonian promoters, XVIII $^{\text {th }}$ and XIX ${ }^{\text {th }}$ century.

\footnotetext{
${ }^{1}$ Quiero mostrar mi agradecimiento a Luis Alonso Alvarez y a Elvira Lindoso Tato de la Universidad de A Coruña por facilitarme el camino para que pudiera realizar este artículo. Ahora bien, los errores que, muy a mi pesar, pudiera contener este artículo son de mi exclusiva responsabilidad.
} 
La inmigración masiva catalana a Galicia desde mediados del siglo XVIII constituyó un caso insólito dentro de la historia de los movimientos demográficos, pues más de 15.000 mercaderes e industriales se desplazaron a una tierra más atrasada económicamente que la de su lugar de origen para desempeñar sus actividades comerciales $^{2}$. En este sentido hay que tener en cuenta que los gallegos estaban acostumbrados a ver marchar sus gentes desde tiempos inmemoriales pero no a recibir foráneos en busca de fortuna.

Las primeras oleadas migratorias catalanas tenían carácter estacional, es decir, se prolongaban durante las campañas pesqueras pero, una vez finalizadas éstas, emprendían de nuevo viaje de regreso a su tierra natal. Las transformaciones introducidas por estos empresarios catalanes tanto en las artes de pesca como en las prácticas empresariales fueron a menudo objeto de rechazo social, tal y como demuestran los abundantes pleitos y conflictos existentes en el período. Sin embargo, no cabe duda que su llegada supuso un auténtico estímulo desde muchos puntos de vista para la estructura económica de Galicia. Destacados personajes gallegos del siglo de las luces, contemporáneos al proceso, dejaron constancia del impacto que tuvo la llegada de los llamados «fomentadores catalanes» en la sociedad autóctona de la época. Así describía este fenómeno un influyente hombre de su tiempo, el ilustrado coruñés Cornide de Saavedra ${ }^{3}$;

«Vivía esta provincia en el seno de la paz y de la abundancia; gozaba de los frutos de su costa y suelo, sin la angustia de perderlos en el futuro; los exportaba en naves propias a los países extranjeros...; de repente se presentan los industriosos catalanes, esos holandeses del mediodía... que trastornan el comercio de sus naturales, dejándolos en una sujeción precaria, los empeñan en contratos que causan ruina y les anticipan en vinos y aguardientes el valor de su futuro trabajo, vician sus costumbres y fomentan la holgazanería...»

En esta, sin duda, desmedida y apasionada descripción, Cornide deja entrever una idea muy importante que sería corroborada más tarde por otros autores; el atractivo de las salazones era tan solo relativo y guardaba relación con la búsqueda de un producto con suficiente valor añadido como para compensar los retornos de la distribución de vinos y aguardientes catalanes en Galicia ${ }^{4}$. En esta necesidad comercial radica una de las causas principales que explica el porqué muchos comerciantes catalanes eligieron como uno de los puntos de destino de su diáspora

\footnotetext{
${ }^{2}$ Beiras (1995), p. 42. La estimación de la llegada de 15.000 catalanes entre mediados del siglo XVIII y principios del siglo XIX es de Meijide Pardo.

${ }^{3}$ Cornide de Saavedra (1774), Memoria de la pesca de la sardina..., pp. 59-60.

${ }^{4}$ Alonso Alvarez en Pérez Picazo (1996), p. 99.
} 
a Galicia; «(...) y es que en Galicia era posible abastecerse de pescado salado para cubrir el viaje de vuelta, un producto muy apreciado para el consumo en Cataluña» ${ }^{5}$. Como consecuencia, en un principio se trataba por lo general de redes de comerciantes catalanes que, o bien se trasladaban o bien establecían contacto con algún agente, a menudo también de origen catalán, desplazado a tierras gallegas. Formaban de esta manera compañías que aprovechaban los jugosos beneficios que proporcionaba el intercambio de vinos y aguardientes por salazones y coloniales.

A finales del siglo XVIII muchos de estos desplazamientos temporales se convirtieron en definitivos. Así, un alto porcentaje de catalanes echó raíces en los principales puertos y villas marineras de Galicia. La ciudad de A Coruña no permaneció ajena a todo este fenómeno. Sobre todo desde el establecimiento de los Correos Marítimos coruñeses ${ }^{6}$ (1764) y, posteriormente, con la entrada en vigor de los Decretos de Libre Comercio (1788) -que situaban al puerto gallego como un punto de partida alternativo a Cádiz para el comercio colonial-, esta ciudad se fue convirtiendo en un eslabón de enlace clave en la cadena comercial establecida entre Cataluña y América. Tal y como señala Tettamancy ${ }^{7}$, a lo largo de la segunda mitad del siglo XVIII; «habilitada pues, la Coruña para hacer el comercio de América, conviértese desde entonces en una de las primeras plazas mercantiles de la nación».

Una de las numerosas estirpes que siguió una trayectoria análoga a la anteriormente descrita fue la de Francisco Ferrer y Albà, ejemplo de los tantos hombres de empresa de origen catalán que llegaron a la ciudad herculina en los tiempos del Antiguo Régimen. El estudio de este arquetipo familiar, generación tras generación, enmarcado permanentemente en la coyuntura económica, social y política de la Coruña de la época, será el objetivo principal de este trabajo.

\section{PABLO ALBÀ Y EL ESTABLECIMIENTO DE UNA RED COMERCIAL AL ESTILO «HOLANDÉS»}

A mediados del siglo XVIII se multiplican las informaciones referentes a amplias redes de negociantes catalanes que se extienden a lo largo de todo el territorio peninsular. El dominio catalán de estos ejes comerciales establecidos entre Cataluña y el resto de España, y las peculiaridades de sus operaciones han provocado que muchos

\footnotetext{
5 Traducción propia desde Torras (1987), p. 13.

${ }^{6}$ Alonso Alvarez (1986), pp. 50-51. «Los Correos Marítimos tenían como función primordial conducir la correspondencia oficial y privada entre la metrópoli y sus colonias. No obstante, esta actividad va a quedar desbordada por la superioridad que alcanza el transporte de mercancías».

${ }^{7}$ Tettamancy y Gastón (1900), p. 287.
} 
autores hayan encontrado ciertas semejanzas entre este fenómeno y aquel otro que habían vertebrado los holandeses mucho tiempo atrás; «los emigrantes catalanes salían más bien para ir tejiendo la red de relaciones que necesitaba una economía en transformación y que extendía cada vez más su ámbito de operaciones» ${ }^{8}$.

El comercio de aguardientes fue una de las primeras actividades mercantiles en las que los comerciantes catalanes establecieron esas relaciones inter-regionales. La libertad de fabricación y extracción de aguardientes, aprobada en 1746, impulsó a los abundantes productores catalanes de este tipo de artículos a competir en mercados exteriores. Con este propósito Pablo Albà, natural de Vilanova de Cubelles, estableció una sociedad mercantil de vinos, aguardientes y pesca salada junto a Joan Barreras en A Coruña a mediados del siglo XVIII. Este acontecimiento constituía el comienzo del que sería un largo y fructuoso contacto comercial entre los dos pueblos. Esta sociedad inicial se fue renovando sucesivamente e incluso, a mediados de los sesenta, Pablo Albà llegó a asociarse con un funcionario de la Real Hacienda y con un grupo de mercaderes autóctonos con la finalidad de importar vinos del Campo de Tarragona y el Cantábrico -donde también vendía salazones gallegas- con retornos de pesca salada y cacao ${ }^{9}$.

Albà y sus socios tenían garantizada la colocación de sus productos en los múltiples establecimientos y tabernas existentes en la ciudad herculina porque lograron hacerse, en la mayor parte de este período, con el arrendamiento del abastecimiento de vinos y licores en esta urbe ${ }^{10}$. La empresa fue creciendo en beneficios y socios a lo largo de los años setenta. El volumen de negocios debió de ser importante cuando, en los inicios de la década de los sesenta, Pablo Albà decidió alquilar una casa para «poder executar de manera mas adecuada los multiples negocios que le retienen en la ciudad, por ser traficante de barios xeneros» ${ }^{11}$.

En realidad, Pablo Albá maior nunca mostró intención de asentarse definitivamente ${ }^{12}$ en tierras gallegas. De hecho, en sus largas ausencias trató de no descuidar

\footnotetext{
${ }^{8}$ Traducción propia de Torras (1987), pp. 13-14. Una excelente síntesis de las características, causas y consecuencias de la emigración catalana por el resto del territorio peninsular en el siglo XVIII se encuentra en J. Torras, en Pérez Picazo (1996), pp. 27-30.

${ }^{9}$ Archivo del Reino de Galicia (en adelante ARG), Pillado, Particulares leg. 11.827/5, pp. 2-10.

${ }^{10}$ ARG, Pillado, Particulares, leg. 12.357/34, pp. 2-6. Pablo Albà y sus socios (Joseph Goel, Cañellas, Fontanals...) tuvieron que hacer frente a un pleito en 1769 con el fiscal de S.M «a consecuencia de los precios abusivos a los que vendían el vino aprovechando su situación de unicos vendedores de vino y aguardientes de otro Reyno en la ciudad, provocando la ruina de los taberneros y comerciantes minoristas».

${ }^{11}$ ARG, Pillado, Particulares leg. 11.827/5. Primero alquiló una casa en la Rúa Nueva y, más tarde, alquiló otra en la calle Real por dos años (1763-65) al pago de 50 ducados de vellón.

${ }^{12}$ ARG, Particulares, leg. 11.827/5. De hecho en A Coruña no llegó a adquirir vivienda en pro-
} 
los negocios familiares relacionados fundamentalmente con los viñedos y las transacciones comerciales en Vilanova. Tal y como detalla el Almanak Mercantil ${ }^{13}$ en 1805; «el principal comercio de la Plaza de Vilanova i la Geltrú consiste en la extracción de vinos, aguardientes y demás frutos del país que se embarcan en esta playa para Galicia, las Américas y las provincias del Norte... y comercian por compañías establecidas en quasi todas las partes de nuestras Américas como también en Galicia para el tráfico de sardina». Siguiendo una estrategia familiar, su hijo, Pablo Albà menor, recogería el testigo de estas actividades mercantiles en Cataluña. Por otro lado, su hijastro, Francisco Ferrer y Albà ${ }^{14}$, se pondría al frente de los negocios en A Coruña. Seguramente, las buenas expectativas de beneficios de la empresa familiar en el puerto gallego junto con la necesidad de contar con un comisionario de confianza en la plaza influyeron en la toma de esa decisión ${ }^{15}$.

\section{LA DIVERSIFICACIÓN DE LOS NEGOCIOS FAMILIARES; FRANCISCO FERRER Y ALBÀ MAIOR}

Francisco Ferrer y Albà llegó con apenas diez años a la ciudad de A Coruña hacia 1757 de la mano de su padrastro Pablo Albà, con el que colaboraba en la tareas mercantiles y sólo «muy de vez en cuando volvía a su tierra para ver a su madre» ${ }^{16}$. A finales de los sesenta, al llegar Pablo Albà a una edad avanzada, deci-

piedad, y parte de lo recogido en sus negocios durante su estancia en la ciudad iba destinado a Vilanova donde estaba construyendo dos casas para vivienda futura. Su mujer, María Albà, permaneció también en Cataluña mientras Pablo gestionaba sus negocios en Galicia. Su intención, por tanto, nunca fue la de emigrar definitivamente.

${ }^{13}$ Almanak Mercantil, 1805, p. 337.

${ }^{14}$ ARG, Particulares, leg. 11.827/5, fol. 108. Francisco Ferrer y Albà era hijo de Francisco Ferrer y María Albà, quien enviudó del primero y se volvió a casar en segundas nupcias con Pablo Albà de quien tuvo varios hijos.

${ }^{15}$ En 1785 tenemos constancia de que se estableció una compañía (sociedad colectiva) por cinco años compuesta por tres socios; Francisco Ferrer y Albà, Pablo Albà y Juan Brunet, todos de Vilanova i la Geltrú en la que el primero actúa como director. El capital de la misma era de 194.208 reales de vellón y los beneficios se repartían en; 3/8, 3/8 y 1/4 respectivamente. La escritura pública se firmó ante el notario Gerardo Cassani en Vilanova el 6 de Julio de 1785. La finalidad de la compañía era la actividad comercial de aguardientes, vinos y salazones entre Galicia y Cataluña. Pablo Albà menor se encargaba de la emisión de la mercancía en Vilanova y los otros dos socios, residentes en A Coruña, se ocupaban de su comercialización en esta plaza. Los tres socios eran familiares; Francisco y Pablo hermanos y Juan su cuñado (casado con María Albà, hermana de los primeros). Todos originarios de Vilanova. AHPC (1793), Not. Baltasar de Pazos, Protocolo 6755, fols. 210-14.

${ }^{16}$ ARG, Particulares, leg. 11.827/5, fol. 104. Donde se afirma (1763) que «habera como cosa de seis años ha venido de su tierra a esta ciudad en compañía de su padrastro». 
dió terminar sus diásporas y permanecer en Cataluña, quedando al cargo de los intereses familiares en la ciudad su hijastro Francisco. Así, por los años ochenta tomó carta de avecinamiento ${ }^{17}$ en A Coruña Francisco Ferrer y Albà, formando parte de una oleada de negociantes foráneos más heterodoxos que los grupos oligárquicos ${ }^{18}$ que, hasta ese momento, habían controlado mayoritariamente las actividades económicas en esta ciudad. Poco a poco se fue abriendo camino en los círculos empresariales de la urbe ejerciendo un amplio abanico de actividades en el ámbito comercial que lo convertirían en un reconocido hombre de negocios. A pesar de su progresión económica y social no olvidó las actividades familiares que lo habían traído a la misma ${ }^{19}$. En este contexto actuó frecuentemente como asentista, esto es, contrataba con el gobierno la provisión o suministros de víveres para la plaza de la ciudad y también introducía tejidos catalanes destinados a la venta al por mayor ${ }^{20}$.

A medida que prosperaba en sus negocios, Francisco Ferrer y Albà iba diversificando sus actividades comerciales y financieras, tal y como hacían la mayor parte de los comerciantes de origen catalán que decidían establecerse en la ciudad. De esa manera nuestro protagonista se fue introduciendo progresivamente en nuevas ramas económicas que, además de ampliar sus horizontes empresariales, le proporcionaban un importante incremento de los beneficios. Así, en 1794 entró a formar parte del grupo financiero creado en torno a la Sociedad de Seguros Marítimos Purísima Concepción de María Santísima y Apóstol Santiago I y III, en la que inicialmente Ferrer y Albà participaba con dos acciones. Entre los socios de este grupo podemos encontrar tanto a grandes y pequeños comerciantes afincados en A Coruña como a los principales hacendados y rentistas de la ciudad, junto con un grupo de negociantes vinculados a experiencias industriales, básicamente de la salazón. Esta estructura nos permite constatar las estrechas relaciones que Ferrer y Albà

\footnotetext{
${ }^{17}$ Meijide Pardo (1995), p. 101.

18 Alonso Alvarez (1986), p. 156. Heterodoxos en el sentido de que los nuevos negociantes representaban una nueva mentalidad de hacer negocios que, además, iba acompañada de actitudes económicas e ideología liberal, alejándose, por tanto, del sistema de privilegios comerciales propio del absolutismo. Un sistema que había caracterizado los negocios de la ciudad herculina en las décadas anteriores.

${ }^{19}$ Las asociaciones en compañías con Pablo Albà y otros comerciantes de origen catalán afincados en A Coruña se siguieron sucediendo. En 1802 hay constancia de una compañía establecida entre Pablo Albà, Ferrer y Albà y José Carbonell de las mismas características que las descritas en la nota 15. AHPC, Not. Roque de Noya y Verea (1802), Protocolo 6830, fol. 247.

${ }^{20}$ Carmona (1990), p. 211. Este autor explica las formas más habituales de comercialización de los tejidos catalanes en Galicia; «En sociedades mayoritariamente comanditarias, donde figuraba por una parte algún comerciante avecindado en Galicia y por otra la firma catalana...». Se puede observar que la fórmula es similar a la del comercio de vinos y salazones. De todas formas el predominio del tejido catalán en Galicia será más tardío, alrededor de la segunda mitad del siglo XIX.
} 
había conseguido establecer con el tejido empresarial de la urbe. La finalidad de esta Compañía comprendía;

«el adelantamiento de los intereses y beneficio común del comercio para que, por medio de la misma, todas las personas adentro y fuera de esta ciudad que comercien, tanto en las Américas como en las demás partes de Europa, puedan asegurar embarcaciones mayores, menores, bien sean de Guerra o particulares, sus caudales, ya consten en dinero o en mercancías, frutos, y efectos de todas clases» ${ }^{21}$.

Hay que tener en cuenta que las sociedades de seguros se desarrollaron sobre todo con el crecimiento comercial que tuvo lugar después de la Guerra de Independencia norteamericana y «desempeñaron un importante papel en el comercio, sobre todo transoceánico, al permitir compensar las catástrofes navales, uno de los mayores obstáculos que desviaban la inversión en el sector» ${ }^{22}$. Se convirtieron además, en una interesante vía alternativa de obtener beneficios para la clase empresarial.

Vinculado también al negocio naviero, Francisco Ferrer y Albà participó en sociedad como propietario de varios barcos como las fragatas Carmela y María Pita $^{23}$, entre otras, con las que, además del lógico transporte de mercancías, practicó el corso en los tiempos de guerra. Esta actividad mercantil, habitual durante los continuos conflictos bélicos que se sucedieron en esta época, consistía en la persecución y apresamiento de navíos de potencias enemigas con el respaldo administrativo y militar de la monarquía ${ }^{24}$. Los beneficios que proporcionaban estas capturas servían para compensar las pérdidas por la paralización del tráfico comercial en los años de conflicto.

«... Asimismo se ha visto la Real Orden de S.M. comunicada por el Exmo Marqués de Sonora a este Real Consulado propagando la gracia por un año más para que puedan sus Basallos adquirir embarcaciones extrangeras con libertad de dueños con

${ }^{21}$ Archivo Histórico de Protocolos de A Coruña (en adelante AHPC), Not. Baltasar de Pazos (1794), Protocolo 6757, fol. 64. El hecho de que participe tan solo con dos acciones no debe minusvalorar la importancia de su intervención, pues el capital de estas sociedades estaba muy repartido y ninguno de los socios poseía más de ocho acciones.

${ }^{22}$ Alonso Alvarez (1986), p. 145.

${ }^{23}$ AHPC, Not. Fernández Bó (1813), Protocolo 7922, fol. 50. Respecto a los intercambios comerciales con América, hay referencias de que Francisco Ferrer y Albà recibió en 1804 dos remesas monetarias procedentes de Montevideo; una de 23.600 reales de vellón y otra de 16.000 reales de vellón que transfirió hacia Barcelona, seguramente a su hermano Pablo Albà por la participación que éste tenía en el negocio familiar. Cifras nada desdeñables para la época. Información procedente de los informes y las correspondencias consulares, cortesía del prof. Luis Alonso Alvarez.

${ }^{24}$ Alonso Alvarez (1986), p. 219. Entre 1798 y 1818 Francisco Ferrer y Albà fue uno de los armadores de corso que mayor número de licencias obtuvo, al menos ocho en ese período. 
lo que mas comprehende y beneficiarse lo mas que puedan de ello, y la Junta acordó se guarde y cumpla lo resuelto por S.M. y se publique por edictos en esta ciudad y Distrito del Consulado» ${ }^{25}$.

Además de las actividades navieras y comerciales Ferrer y Albà decidió probar fortuna en las salazones. A finales del siglo XVIII compró una fábrica de sardina y un almacén en la Palloza, emplazamiento habitual de este tipo de industrias en la Coruña de la época. En este almacén depositaba gran cantidad de sal, necesaria para la conservación de pescado, los palos campeche (madera utilizada, entre otros usos, para la fabricación de toneles y la tintura de telas) y todo tipo de mercancías destinadas al comercio dentro y fuera de la ciudad (bretañas, ropas confeccionadas, jabón...). En esta nueva empresa contaba con la colaboración de uno de sus yernos; Isidoro Arias, comerciante de origen vallisoletano (Medina de Rioseco), así como también de su hijo Francisco Ferrer y Albà menor, quien entró a formar parte de ella posteriormente. Los tres actuaban en compañía a razón de tercias partes de beneficios, dedicados a negocios industriales y comerciales en la plaza coruñesa y manteniendo el contacto mercantil con Cataluña a través del hermano y tío respectivo de los interesados, Pablo Albà26.

La descripción de esta Compañía responde al esquema típico de las sociedades coruñesas de la época; empresas de carácter colectivo, compuestas por un número pequeño de socios (habitualmente dos o tres) que a menudo están unidos por lazos familiares y en los que no siempre está presente la escritura pública (lo que dificulta el estudio de la estructura de capitales). El reparto de beneficios se establecía usualmente de manera igualitaria (medias, tercias partes...) ${ }^{27}$.

Como muestra de su progresión en las actividades mercantiles de la ciudad de A Coruña Ferrer y Albà maior aparece matriculado en esta Plaza en calidad de mercader, tal y como consta en el Real Consulado de la ciudad en el año

${ }^{25}$ Biblioteca del Consulado (en adelante BC), Actas Libro I (1785-1794), p. 11.

${ }^{26}$ Francisco Ferrer y Albà maior se casó con Francisca Artiaga Beitia una mujer perteneciente a una familia acomodada de origen asturiano. Fruto de este matrimonio tuvieron tres hijos; Rosa y M. ${ }^{\mathrm{a}}$ Ignacia casadas con Juan Cañellas e Isidoro Arias, las cuales murieron prematuramente (antes que su propio padre; en 1803 y 1806 respectivamente) dejando dos hijos cada una (Rosa y Damiana, la primera y Francisco y Nicolás la segunda) y Francisco Ferrer y Albà, el único hijo varón que continuaría la estirpe. Según consta en distintos documentos, las relaciones entre el suegro y los yernos eran muy buenas, compartiendo casa y negocios con total confianza sin necesidad de efectuar escrituras públicas. AHPC, Not. Fernández Bó (1813), Protocolo 7922, fol. 50.

${ }^{27}$ Alonso Alvarez (1986), pp. 112-116. Este autor añade además que las características descritas (sociedades mayoritariamente colectivas, pocos socios...) no se correspondían con las existentes en la época en otras regiones de España, como por ejemplo Cataluña. Esto podría explicarse por un mayor retraso de las instituciones comerciales gallegas. 
179628. El Real Consulado Marítimo y Terrestre comprensivo de la ciudad de la Coruña, su Puerto, el de Vigo, y todos lo puertos y pueblos del Arzobispado de Santiago fue una institución de gran prestigio creada por Cédula de 29 de Noviembre de 1785 por el rey Carlos III para fomentar el tráfico mercantil, protegiendo la industria y procurando el bienestar de la agricultura ${ }^{29}$. Una tarea que llevó a cabo con empeño hasta su temprana desaparición en 1829.

«Componíase el Consulado, en mal hora suprimido bastantes años después, de hombres notables, no solo por su talento sino también por su patrimonio... Contaba de un prior, dos cónsules y ocho consiliarios, un secretario escribano, un contador, un tesorero, un juez de alzadas y un asesor; y para el servicio de las funciones judiciales, dos porteros y un guarda de almacén $»^{30}$.

Los consiliarios o personas elegidas para asistir a las Juntas y tomar parte en las decisiones como consejeros estaban distribuidos por ramas de actividad; caballeros hacendados, comerciantes, mercaderes, navieros y fabricantes. Más tarde, a principios del siglo XIX, Francisco Ferrer y Albà formó parte de la Junta de Gobierno del Real Consulado como consiliario de mercaderes ${ }^{31}$. En realidad, la Casa de Comercio de Francisco Ferrer y Albà estaba considerada como una firma de solidez mediana dentro del conjunto de Casas que actuaban en A Coruña a finales del siglo XIX. Así consta en el informe enviado desde esa Plaza a los directores del Banco Nacional de San Carlos. Una comunicación que debía despachar cada Plaza comercial del país con periodicidad anual, y que servía al Banco Nacional para establecer los límites de crédito y descuento de letras que debían de darse a cada firma con relación a su solvencia ${ }^{32}$.

La transición secular estuvo marcada por la crisis del comercio colonial y las frecuentes y costosas guerras exteriores, esencialmente con Inglaterra, que exigían continuos empréstitos y peticiones de colaboración por parte de la Corona. A estas regias llamadas de auxilio solían responder los empresarios más reputados de la ciudad a título personal o colectivo, y entre ellos, por supuesto, figura repetidamente nuestro protagonista ${ }^{33}$.

\footnotetext{
${ }^{28}$ Almanak Mercantil (1796), p. 347.

${ }^{29}$ Tettamancy (1900), p. 297. Para ver información más detallada sobre la creación y funcionamiento del Real Consulado de A Coruña; Rodríguez Varela (1977) y Sánchez Rodríguez de Castro (1992).

30 Tettamancy (1900), p. 298.

${ }^{31}$ Almanak Mercantil (1806), p. 244.

${ }^{32}$ Cortesía de prof. J. C. Maixé. Banco de España. Informes sobre Casas de Comercio, Año 1796, A Coruña. Francisco Ferrer y Albà aparece clasificado en la segunda de las tres clases en las que se catalogan las Casas de Comercio que trabajan en A Coruña según su solidez (alta, mediana o ínfima).

33 «El Real Consulado valoraba en más de ocho millones de reales las cantidades de las que se
} 
A pesar de que la coyuntura económica no era la más adecuada, los negocios de Ferrer y Albà parecían marchar bien. Así lo demuestra el hecho de que, en 1804, compró una Casa Grande en el Cantón Pequeño número 12, situada en una zona privilegiada de la ciudad y en pleno barrio de la Pescadería, donde habitaba la mayor parte de la clase mercantil. Estaba valorada en 119.094 reales de vellón y 30 maravedíes, y llevaba a su cargo el gravamen de un censo de 903 reales de vellón y 5 maravedíes anuales al Capellán de la Parroquia de San Esteban de Culleredo, que redimió y extinguió el comprador en el momento de la adquisición. Se venía a unir a un patrimonio familiar que ya contaba con otra Casa Pequeña, en la que hasta entonces habitaban, situada en el mismo Cantón nombrada con el número 23 y de menor valor que la primera. La nueva vivienda se convertiría, tras numerosas obras de reforma y mejoras, en la sede empresarial del grupo familiar ${ }^{34}$.

Las mayores dificultades aún estarían por llegar, pues la Guerra de Independencia exigiría un esfuerzo todavía mayor de los habitantes de la ciudad. Las Contribuciones Extraordinarias de guerra en ese período obligaban a pagos semestrales de cuantía fijada individualmente en relación con los bienes y rentas que cada habitante poseía, según hubieran dejado constar en una declaración jurada de su riqueza. Así lo ordenaban los Reglamentos para el arreglo y exacción de la Contribución Extraordinaria de Guerra ${ }^{35}$. Todos los ámbitos sociales y políticos de la urbe estaban incluidos en esta normativa; eclesiásticos, hacendados, comerciantes, artesanos, jubilados... La única excepción eran aquellos individuos que se declaraban y demostraban su estado de pobreza e indigencia. Incluso el Consulado de A Coruña puso en manos del ejército gallego un millón de reales, recaudados a través de subscripciones voluntarias de los comerciantes ${ }^{36}$.

Francisco Ferrer y Albà formaba parte de los 125 comerciantes de la Plaza que sumaban en conjunto una renta anual de 2.474.200 reales y, en base a ella, se les asignó una cuota global de 108.276 reales. En total, los comerciantes coruñeses sufragaron el $27 \%$ de las cantidades destinadas a financiar la lucha contra los fran-

desprendió la ciudad en calidad de préstamo, junto con otras importantes sumas entregadas como donativo para las guerras y las expediciones de ultramar». Lindoso Tato (1996), p. 27. Para una información más detallada sobre la financiación de la Guerra de la Independencia en el ámbito nacional, véase Fontana (1981).

${ }^{34}$ AHPC, Not. Ruperto Suárez (1859), Protocolo 9703, fols. 8-20.

${ }^{35}$ Archivo Histórico Municipal de A Coruña (en adelante AHMC), Hacienda Contribuciones, Caja 10. Aunque la declaración de su riqueza era de carácter obligatorio y bajo juramento, es evidente que esta fuente fiscal no es fiable para estimar las rentas que anualmente obtenía cada comerciante. Como es lógico, el fraude y ocultamiento de bienes eran frecuentes; aquél que ingresaba menos tendría que contribuir a los gastos de guerra en una proporción menor.

36 Tettamancy (1900), p. 406. 
ceses. Ferrer y Albà declaró una renta anual de 12.000 reales de vellón. Tomando como referencia esta cifra, le correspondió una cuota de 525 reales en el año 1809 , como contribución para «la liberación de la patria» ${ }^{37}$. Estos últimos acontecimientos sorprendieron al patriarca viudo y en edad avanzada, tal y como declaraba en el testamento que otorgó ante el Notario Antonio Pardo en $1806^{38}$;

«Hallándome en cama de enfermedad natural pero en mi sano juicio y entendimiento... receloso del tremendo golpe de la muerte, y que mis cosas queden dispuestas segun el recto orden de Dios hago y otorgo este testamento... nombro y elijo por mis unicos y universales herederos al expresado mi hijo, Francisco Ferrer y Albà y a los referidos nietos... de todos mis vienes presentes y futuros, derechos y acciones para que los dividan igualmente por tercias partes amistosamente sin pleito ni cuestión»

La muerte le sobrevino poco tiempo después, en plena Guerra de Independencia y, posteriormente, en 1813, se realizó el inventario y partijas de su herencia. Fue enterrado, siguiendo su deseo expreso, en la Capilla de San Jorge. El Cuerpo de herencia estaba valorado en 608.836 reales de vellón y 28 maravedíes repartidos de la forma que sigue ${ }^{39}$ :

\section{Cuerpo de la Herencia de Francisco Ferrer y Albà maior}

(en reales de vellón y maravedíes)

\begin{tabular}{lc}
\hline Ingresos de las actividades comerciales en la Plaza de Coruña y en Cataluña & $148.631,, 20$ \\
Inversión de Ferrer y Albà en la Compañía establecida con su hijo, yerno y hermano & 42.500 \\
Efectos comerciales en almacén (vinos, aguardientes, jabones, paños y ropas) & $175.888,, 32$ \\
Aparejos de pesca en almacén (usados) & $12.313,1$ \\
Ingresos por intereses de vales reales y pagarés & $5.107,, 12$ \\
Dinero en metálico & 16.668 \\
Enseres y ropas & 7.200 \\
Ingresos por deudas pendientes de las actividades comerciales & $35.676,3$ \\
& 443.985
\end{tabular}
Tato.

${ }^{37}$ AHMC, Guerra de Independencia (1809), cortesía de Luis Alonso Alvarez y Elvira Lindoso

${ }^{38}$ ARG, Protocolos, Not. Antonio Pardo (1806), fols. 153-154. Los testamentos y codicilos nos permiten conocer en muy pocos casos el inventario de bienes y su principal información es de origen genealógico. A este respecto son de mucha mayor riqueza los inventarios post mortem y las escrituras de partijas, donde sí se solían detallar los bienes y rentas del fallecido.

${ }^{39}$ Elaboración propia a partir del inventario p.m. con referencia en AHPC, Not. Fernández Bó (1813), Protocolo 7922, fol. 50. 
Vales reales y pagarés de consolidación

Valor de fincas*

- Casa Grande Cantón pequeño, n. ${ }^{\circ} 12$

100.000

- Casa Pequeña Cantón Pequeño, n. 23

15.000

- Almacén y Fábrica de salazón en la Palloza

60.000

Total fincas

175.000

Créditos pendientes a favor de la herencia

$9.054,, 32$

Total a sumar como Cuerpo de la Herencia

$680.512,26$

\section{$\underline{\text { A restar }}$}

Créditos pagados por la herencia

Créditos a favor de la herencia dados por perdidos

Total a restar al Cuerpo de la Herencia

\footnotetext{
* Nota: acuerdan rebajar la tasación de las fincas «debido a que con las penosas circunstancias de los tiempos no abría quien las tomare por su verdadero valor que es mucho maior».

* Nota: hay errores en la suma original del inventario original que refleja la cantidad total líquida de $608.836,9$ que no coincide exactamente con la resultante después de la corrección. Hay que tener en cuenta que un real de vellón era equivalente a treinta y cuatro maravedíes.
}

Tal y como había deseado el difunto se hicieron tres lotes de igual valor, 202.945,,14 reales, que echaron a suertes los beneficiarios. Al único hijo varón, Francisco Ferrer y Albà menor le tocó el primer grupo compuesto por;

\section{Primer grupo del lote correspondiente a Francisco Ferrer y Albà menor}

(en reales de vellón y maravedíes)

La Casa Grande sita en el Cantón Pequeño de la Pescadería de esta ciudad con n. ${ }^{\circ} 12 \quad 100.000$

Parte de las ropas, muebles y otros... de la herencia

Vales reales (uno de 200 pesos y otro de 300)

$13.552,, 32$

Pagaré de la Diputación de Madrid

Dinero metálico 
Con esta considerable herencia y aquella otra de menor valor procedente de la legítima materna ${ }^{40}$, emprendió Francisco Ferrer y Albà menor sus negocios mercantiles en solitario, siguiendo la senda de su difunto padre. La aventura empresarial no le era desconocida puesto que, desde muy joven había venido trabajando en estos menesteres, a través de sociedades familiares. Esta formación le había permitido acumular una notable experiencia así como también importantes beneficios.

\section{LA PROYECCIÓN SOCIAL Y POLÍTICA DE FRANCISCO FERRER Y ALBÀ MENOR EN LAS ELITES BURGUESAS DE LA CIUDAD A PRINCIPIOS DEL SIGLO XIX}

Francisco Ferrer y Albà menor había nacido en A Coruña allá por el año 1779. Constituía, por tanto, la primera generación de esta familia de fomentadores de origen catalán pero de cuna gallega. Se casó muy pronto con una joven de la burguesía coruñesa, M. ${ }^{a}$ Magdalena Andrea Gundián y Carrais, hija del Procurador de la Real Audiencia del Reino en esta ciudad, José Francisco Gundián y Bañales ${ }^{41}$. Tras la muerte de su padre, comenzó a prosperar rápidamente en los negocios, a pesar de la difícil coyuntura económica. Por un lado, la Guerra de Independencia aún no había acabado y las cuotas de las contribuciones extraordinarias de guerra seguían castigando los bolsillos de los ciudadanos ${ }^{42}$. Por otro lado, los Decretos de comercio libre junto con la emancipación de algunos territorios de ultramar ocasionaban la progresiva quiebra del comercio colonial. Todos estos acontecimientos provocaron que el Censo Consular de comerciantes gallegos se redujera en más de un $60 \%$ entre 1807 y 1815. La actividad mayoritariamente elegida por los comerciantes que pudieron sobrevivir en estos difíciles tiempos fue el ejercicio de corso y mercancía. En realidad, esta nueva variedad de «corso mixto» se convirtió en una forma encubierta de comerciar con América ${ }^{43}$.

Precisamente, a lo largo de estos años es posible encontrar numerosas referencias notariales de escrituras de compras y contratas de barcos, así como de solicitudes de Real Patente de Corso y Mercancía relacionadas con Francisco

\footnotetext{
${ }^{40}$ La legítima materna recibida a la muerte de su madre Francisca Artiaga Beitia, a principios del siglo XIX, fue de 20.000 reales de vellón.

${ }^{41}$ AHPC (1818), Not. Gerónimo Suárez, Protocolo 8327, fol. 113.

42 Tal y como muestra la carta de pago de la cuota del segundo semestre de la Contribución Extraordinaria de Guerra de Independencia en 1813, donde Francisco Ferrer y Albà pagó 778,,10 reales. AHMC, Hacienda Contribuciones Caja 10.

${ }^{43}$ Alonso Alvarez (1986), p. 221.
} 
Ferrer y Albà ${ }^{44}$. Los beneficios acumulados debieron ser muy importantes porque este tipo de actividades se extendieron hasta finales de los años veinte.

«No se tratará solo de armar las naves para defender la mercancía en la cada vez más difícil travesía colonial, sino y sobre todo que estamos ante una diversificación de las actividades mercantiles como resultado de las dificultades crecientes en realizar apresamientos conforme la inseguridad en los mares se prolongaba $»^{45}$.

Sin embargo, ésta era sólo una de las múltiples fuentes de ingresos de Francisco Ferrer y Albà, quien regentaba además una gran variedad de negocios mercantiles. Por un lado, y a través de los contactos comerciales con los familiares de Vilanova, recibía las pipas de vino tinto catalán y aguardientes para el abastecimiento al por mayor de la plaza y otros pueblos del país como Mondoñedo o Vivero. A cambio de estas mercancías enviaba retornos de pesca salada y coloniales ${ }^{46}$. Por otro lado, decidió impulsar simultáneamente su actividad industrial comprando un almacén en la Plaza de la Palloza (que lindaba con la Fábrica Nacional de Tabacos de la Palloza que había comenzado a funcionar en 1804), para convertirlo en fábrica de sardina con todos los enseres necesarios y sus lagares. Almacén, al que pronto se uniría otro de similares características en el puerto de Fontán en el que invirtió parte de lo recibido de la herencia pater$\mathrm{na}^{47}$.

44 AHPC, Not. Andrés Antonio de Leyes Lourido: Referentes a compras de barcos (1808-1818), Protocolos 8057, fol. 454; 8059, fol. 290; 8060, fol. 151. Referentes a contratas de barcos (1815-18), Protocolos 8062, fol. 108, fol. 121; 8063, fol. 72; 8064, fol. 119; 8065, fol. 152. En particular, «el bergantín Roncales, propiedad de Francisco Ferrer y Alba esta armado y se halla proximo a dar la vela para Lebante con sardina y otros efectos. AHPC, Not. Andrés Antonio de Leyes Lourido, Protocolo 8055, fol. 32.

45 Alonso Alvarez (1986), p. 221.

${ }^{46}$ Según los libros de contabilidad de Miguel Colomer las exportaciones de pesca salada gallega enviadas por Francisco Ferrer Albà a Barcelona entre 1819 y 1820 ascendieron a 9 cascos de sardinas (equivalentes a 1.571 libras catalanas) y 18 fardos de pulpos, tal y como ha recogido Luis Alonso Alvarez (1976), p. 224. Los negocios comerciales con sus familiares catalanes siguieron realizándose en régimen de sociedad accidental, esto es, sin establecer compañía formal, contribuyendo en una parte del capital y repartiéndose los beneficios y las cargas en la proporción que hubieran establecido. Era ésta, la del compromiso privado, una práctica muy habitual en los negocios mercantiles de la época. Lindoso Tato (1996), p. 38.

${ }^{47}$ AHPC, Not. Fernández Bó (1813), Protocolo 7922, fols. 53-55. Francisco Ferrer y Albà «Compra el Almacén o fábrica de sardina a los herederos de Francisco Gurrea, vecino de la ciudad, por valor de 35.000 reales de vellón en monedas de plata». 
Los puertos de Fontán y Sada situados en una ría cercana a la ciudad de A Coruña eran unos de los pueblos pesqueros de mayor trascendencia de la provincia. Tal y como afirmaba Larruga; «de ellos hacen los catalanes gran salazón y la extraen para Cataluña y otras partes» ${ }^{48}$. Efectivamente, estos pequeños puertos de mar se convirtieron en emplazamientos habituales de los fomentadores catalanes quienes, seguramente por la riqueza de sus aguas y su cercanía al puerto de A Coruña, encontraron en ellos una ubicación ideal.

«Cabe añadir que los matriculados sadenses ajustaban instrumentos notariales de compañía, por espacio de un cuatrienio para redar la sardina, con los llamados fomentadores o compañías de catalanes, dueños de las fábricas de salazón. A éstos iba a parar, vendida en fresco y a buen precio, la mayor parte de la sardina. Durante las postreras décadas del siglo estaban instalados en Sada y Fontán hasta siete lagares, con sus competentes almacenes dirigidos por otras tantas compañías catalanas, que todos los años embarcaban muy crecido volumen de sardina prensada con destino a la costa del Mediterráneo, sin faltar remesas a puertos del Cantábrico e incluso a los mercados de las Indias...» 49

Al éxito de los negocios que acompañó e hizo prosperar la empresa de Francisco Ferrer y Albà en esta difícil coyuntura económica se unió la desgracia personal. En mayo de 1818 enviudó a temprana edad y le quedaron a su cuidado cinco hijos, todos ellos menores de edad; M. ${ }^{a}$ Josefa (16), Juana Rosa (14), Francisco Martín (12), José Nicolás (10) y Ramón Fermín (3). Años más tarde, en 1825, el patriarca decidió hacer escritura de partija con sus hijos para repartirles la legítima materna. Afirmaba ante notario no haberlo hecho antes «porque todos sus hijos hasta aqui han estado a mesa y manteles con el padre pero ahora es justo que cada uno reciba lo que le corresponde...» ${ }^{50}$. En realidad, Francisco Ferrer y Albà se acababa de casar por segunda vez con María Ros y, por ello, veía la necesidad de dejar los asuntos claros ante la previsible llegada de nuevos hijos de este segundo matrimonio. Esta escritura de partijas nos proporciona un excelente recuento de los bienes que formaban parte de su patrimonio en el momento de la muerte de su primera esposa;

${ }^{48}$ Larruga en su obra Memorias políticas y económicas de España (1799), tomo XXXXIV, p. 183 citado por Tettamancy (1900), p. 296.

${ }^{49}$ Meijide Pardo (1995), p. 94. Meijide añade un listado de los fabricantes de sardina ubicados en Sada y Fontán, principalmente de origen catalán, entre los años 1812-1816, donde aparece Francisco Ferrer y Albà.

50 AHPC, Not. Rafael Nogueira (1825), Protocolo 8109, fols. 10-22. 


\section{Inventario de bienes para escritura de partijas}

(en reales de vellón y maravedíes)

\begin{tabular}{|c|c|c|c|}
\hline \multicolumn{2}{|l|}{ Legítimas*: } & \multicolumn{2}{|l|}{ A deducir: } \\
\hline Legítima materna (1) & $22.552,, 17$ & Deudas en contra & $36.982,, 24$ \\
\hline Legítima paterna & $222.945,, 14$ & Depósitos ajenos & 69.000 \\
\hline Total legítimas & $245.497,, 31$ & $\begin{array}{l}\text { Suplido para el entierro } \\
\text { Total }\end{array}$ & $\begin{array}{l}3.110,, 16 \\
109.093,, 6\end{array}$ \\
\hline Memorial de bienes gananciales: & & Líquido gananciales (2) & $431.671,, 6$ \\
\hline $\begin{array}{l}\text { Efectos comerciales } \\
\text { Líquido } \\
\text { Muebles y ropas } \\
\text { Casa en el Cantón pequeño } \\
\text { Fábricas y almacenes de salazón } \\
\text { Goleta Carmen } \\
\text { Deudas a favor }\end{array}$ & $\begin{array}{r}132.190 \\
12.000 \\
10.000 \\
100.000 \\
200.000 \\
60.000 \\
26.574\end{array}$ & $\begin{array}{l}\text { Suma de }(1)+(2) \\
\text { Capitales } \\
\text { Gananciales } \\
\text { Mitad de gananciales } \\
\text { Legítima materna } \\
\text { A repartir entre cinco hijos }\end{array}$ & $\begin{array}{c}454.223,, 33 \\
245.497,, 31 \\
208.726,, 2 \\
104.363,, 1 \\
22.552,17 \\
126.915,, 18 \\
25.383,18\end{array}$ \\
\hline Total & 540.764 & & \\
\hline
\end{tabular}

* Nota: la legítima materna fue la recibida por la difunta Andrea Gundián a la muerte de sus padres en 1811, en la que recibió por suertes el último lote, el quinto, compuesto de tierras, muebles y ajuares, árboles y dinero líquido por el valor que figura en este inventario. En 1829 Francisco Ferrer y Albà tuvo que afrontar una demanda en su contra establecida por uno de sus cuñados acusándole de haberse apropiado de bienes no inventariados (múltiples riquezas de plata y menajes que había en aquella casa) a la muerte de su suegros en complicidad con su cuñado Benito Gundián. Perderá este pleito y tendrá que indemnizarles. ARG. Particulares, Pillado (1829), leg. 23.185, n. ${ }^{\circ}$ 25. La legítima paterna es la mostrada en las páginas anteriores de este trabajo.

** Equivalencia; un real de vellón igual a treinta y cuatro maravedíes.

Tal y como se puede observar en el cuadro anterior, los negocios familiares se repartían, básicamente, en tres grandes ámbitos; las industrias salazoneras, los negocios comerciales y las inversiones navieras. Un trío de actividades desempeñadas frecuentemente por los hombres de negocios de la Coruña de principios del siglo XIX.

El reparto de la legítima a sus hijos tuvo como resultado la merma de aproximadamente una cuarta parte del patrimonio paterno, hecho que no supuso inconveniente para el corriente desempeño de sus actividades empresariales. Más, cuando en 1829 decidió formar sociedad con sus dos hijos mayores Francisco y José «aunque sin solemnizar escritura pública en ahorro de gastos y por confianza en la buena fe recíproca» ${ }^{51}$. Era el nacimiento de la Casa de Comercio con razón social

${ }^{51}$ AHPC, Notario Manuel Lodeiro (1849), Protocolo 8571, fols. 84-85. En 1849 decidieron solemnizar la escritura pública y, por tanto, desde ese momento tenemos constancia oficial de su existencia. Tal y como declaran en ese documento, venían actuando desde 1829 en régimen de sociedad (colecti- 
«Francisco Ferrer y Albà», y sede en la Casa Grande del Cantón Pequeño, n. ${ }^{\circ} 12$ «que ha sufrido mejoras de mucha consideración». Una nueva aventura de este activo hombre de negocios que declaraba que en el momento de establecimiento de dicha sociedad en 1829;

«No tenia mas capital liquido que 5.500 pesos fuertes contando con las 24 onzas de oro que su segunda mujer María Ros aportó al matrimonio pues, aunque eran de su pertenencia diversos inmuebles y fabricas de salazón en el Orzán y Fontán, habiendo sufrido algunas perdidas en estos ultimos años tan duros tenia tomado a interes algunas cantidades las cuales con otras deudas rebajaban en mucho el valor de esas fincas» 52 .

Efectivamente, el fin de la Guerra de Independencia no supuso el retorno de los tiempos esplendorosos de tranquilidad y bienestar económico a la ciudad. Como es sabido, la restauración del despotismo borbónico con la vuelta al trono de Fernando VII estuvo acompañada de varios pronunciamientos que tenían como objetivo el restablecimiento de un régimen liberal que legitimara de nuevo la Constitución de Cádiz de 1812. Uno de los levantamientos más importantes tuvo lugar en la ciudad herculina y estuvo encabezado por Juan Díaz de Porlier ${ }^{53}$, un destacado jefe militar de la guerra contra los franceses. Su insurrección estuvo apoyada por un grupo destacado de comerciantes de la ciudad que financió la revuelta. El resultado de la misma fue el ahorcamiento de su máximo cabecilla, «el Marquesito Porlier» y la persecución y enjuiciamiento de un nutrido grupo de hombres de negocios de la plaza.

No acabarían ahí los disturbios en la agitada ciudad. En los años 1818 y 1819 se produjeron repetidos pronunciamientos militares de carácter liberal que nuevamente fracasaron, hasta que, en 1820, el Comandante Riego se sublevó en la localidad gaditana de San Juan, proclamando la Constitución de Cádiz de 1812. La primera guarnición militar en apoyar esta acción sería la de A Coruña en febrero de ese mismo año ${ }^{54}$. Estos levantamientos culminarían con el inicio del Trienio Liberal (1820-23), un periodo efímero que terminó con un final trágico. El apoyo que

\footnotetext{
va) en la que «el padre participa con mas de la mitad del capital y los dos hijos a partes iguales con la restante».

${ }^{52}$ AHPC, Notario Manuel Lodeiro (1849), Protocolo 8571, fols. 81-83.

53 «Juan Díaz de Porlier había nacido en Cartagena de Indias en 1788 y fue registrado como hijo de un capitán de Infantería y una dama desconocida. Muy posiblemente su identidad fuera la de hijo del Marqués de la Romana, de ahí su apodo popular de 'El Marquesito'. Luchó de manera honrosa y destacada en la Guerra de Independencia y dirigió la insurrección militar liberal tras el final de la misma». V.V.A.A. (1995); Historia de la Coruña, p. 336. Para información más detallada de todo su proceso; Carre Aldao, E. (1915) y Barthèlemy, R. (1995) entre otros.

${ }^{54}$ Según Barreiro (1996), p. 532; «el pronunciamiento de Riego en Cabezas de San Juan hubiera fracasado si el 21 de Febrero de 1820 no se hubiera levantado la ciudad de A Coruña».
} 
las potencias absolutistas europeas prestaron a Fernando VII fue fatídico para el bienestar de este núcleo urbano. La toma de la plaza, donde estaban refugiadas las milicias gallegas, asturianas, vascas y leonesas, por parte de los absolutistas, duró más de un mes ${ }^{55}$. Treinta y cinco días en los que se sucedieron continuos bombardeos que destruyeron edificios y fábricas y un largo asedio que solo la escasez de alimentos, el cansancio de sus habitantes, y la falta de municiones terminaron por vencer. La década posterior estuvo marcada por el exilio, el encarcelamiento y la muerte de buena parte de la sociedad liberal coruñesa. El siguiente fragmento resume el espíritu con el que vivieron los habitantes de la ciudad los aciagos acontecimientos ocurridos en el primer tercio del siglo XIX;

«Continuó la Coruña pasando por los diferentes episodios trascendentales después de la guerra con el francés; apoyando y defendiendo siempre la Constitución de 1812; presenciando con dolor en el 1815 la inaudita ejecución del infortunado caudillo D. Juan Díaz de Porlier, víctima de las malvadas pasiones de la reacción; restaurando en el de 1820 los principios liberales y padeciendo por ellos en el de 1823, en que la industria y el comercio sufrieron tantos quebrantos por las granadas que á la plaza lanzaron las tropas comandadas por Bourcker, parte de aquel ejercito llamado de los Cien Mil Hijos de San Luis que el artero de Fernando VII había procurado falazmente introducir en España para restablecer el régimen absoluto» ${ }^{56}$.

Una vez devuelta momentáneamente la calma en el umbral de los años treinta, comenzó su camino la nueva compañía familiar a la vez que se unificaba la jurisdicción mercantil en España por medio del primer Código de Comercio. Los capítulos 11 y 12 de este Código recogían la obligación de inscribirse en la matrícula de comerciantes de la provincia correspondiente a toda persona que se quisiera dedicar a la actividad mercantil. Una vez aceptada la solicitud, el nombre del inscripto se anotaría en la matrícula general de comerciantes existente en todas las Intendencias del Reino.

«Como requisito previo para formar parte de la referida Matrícula, cada comerciante habría de suscribir un formulario de inscripción (por duplicado), en el que se hacía constar naturaleza, estado civil y clase mercantil que le interesaba ejecutar, y cada una de las solicitudes o declaraciones, acompañada de un oficio del Intendente, se remitía al Jefe Político de la provincia para los efectos prevenidos en el Código de Comercio» 57 .

55 V.V.A.A. (1995), p. 339. El asedio de la ciudad se prolonga desde el 16 de Julio hasta el 21 de Agosto de 1823.

56 Tettamancy (1900), p. 412.

${ }^{57}$ Meijide Pardo (1997), p. 51. 
Cumpliendo la normativa antes expuesta, Francisco Ferrer Albà realizó la solicitud de su matrícula, con fecha de 3 de Mayo de $1830^{58}$. A lo largo de la tercera y cuarta década del siglo XIX, en las que se reactiva el comercio marítimo con América, Francisco Ferrer y Albà combinó su progresión mercantil con la proyección social y política. En el primero de los ámbitos, la actividad giraba básicamente en torno a su Casa de Comercio ${ }^{59}$. A través de la misma emitía numerosas fianzas de Reales Patentes Mercantes y de Corso para barcos que, desde A Coruña, se dirigían en su mayor parte a América con mercancías y pasajeros. Hay, no obstante, también registros de fletes de barcos con destino a puertos españoles como Alicante, Cádiz, Sevilla, San Sebastián o Barcelona que transportaban como principales mercancías; vinos, sardinas o coloniales (cacao, tabaco o azúcar). El valor de la Real Patente dado por el fiador solía corresponder a la mitad del valor del buque en cuestión.

Para el servicio de sus propias transacciones mercantiles con Cataluña y América, Francisco Ferrer y Albà se hizo con un importante patrimonio naviero a lo largo de este período ${ }^{60}$. Así fueron de su propiedad, entre otras, las goletas Santo Cristo de la Salud y Dichosa, junto a los bergantines Aquiles, Casualidad, Coruñés, Fernando VII, Vencejo o Los dos amigos(a) Dolores. Todos ellos combinaban el transporte de mercancías a América, fundamentalmente Cuba y Puerto Rico, con el cabotaje nacional. Era frecuente también el transporte de pasajeros y reclutas hacia los territorios de ultramar. Tal y como afirma Carmona con relación a los años cuarenta del siglo XIX; «la incipiente emigración ultramarina en este periodo fue para unos una tragedia y para otros un negocio» ${ }^{61}$. En referencia a este punto se encuentran numerosos anuncios en el Boletín Oficial de la Provincia indicando la

58 AHMC (1830), Intendencia, Cajas 1.011 y 1.012. En estas cajas se guardan muchos de los impresos originales de matrícula de los principales comerciantes de la Plaza en relación al cumplimiento de la normativa el nuevo Código de Comercio. Entre otros, los del cuñado y el yerno de Francisco Ferrer y Albà; Isidoro Arias y Juan Fernández de Luanco, respectivamente.

${ }^{59}$ La Casa de Comercio Francisco Ferrer y Albà tenía una gran actividad a lo largo de estas décadas, tal y como demuestran la gran cantidad de armadores que confiaban en ella para obtener la fianza necesaria para realizar sus empresas. AHPC, Protocolos 6785, fol. 76; 7734, fol. 122; 7736, fol. 77, fol. 79; 7738, fol. 141, fol. 162; 7740, fol. 1, fol. 6, fol. 8, fol. 10, fol. 23; 7742, fol. 1, fol. 13, fol. 99; 7744, fol. 2, fol. 8, fol. 50; 7750, fol. 56, fol. 90, fol. 95, fol. 97, fol. 99; 7752, fol. 8, fol. 53; 7753, fol. 31 , fol. 56 , fol. 73 ; 8067, fol. 94 ; 8068, fol. 29 , fol. 50, fol. 53, fol. 71; 8107, fol. 13, fol. 32; 7748, fol. 5 , fol. $88 ; 8370$, fol. $29 ; 8338$, fol. 494 , fol. $587 ; 8915$, fol. $42 ; 9140$ fol. 26, fol. 27 , fol. 29 . fol. 7; 9142 , fol. 3 fol. 22 , fol. 99 , fol. 103 , fol. 136 .

${ }^{60}$ Con un patrimonio de buques tan amplio y los continuos viajes, las referencias notariales a este respecto son muy numerosas. Algunas de ellas se recogen a continuación. AHPC, Protocolos 7738, fol. $162 ; 7740$, fol. 10 , fol. $71 ; 7742$, fol. $1 ; 7753$, fol. $73 ; 8068$, fol. $37 ; 8558$, fols. 315-16; 9142 , fol. 103, fol.136; 9146, fol. 6 ; 9150, fol. 39; 9152, fol. 39; 9164, fol. 83 .

61 Carmona (1990), p. 214. 
venta de pasajes con destino a América en la Casa de Comercio Francisco Ferrer y Albà;

Del 15 al 20 del proximo mes, dará vela con destino a Puerto Rico y la Habana el bergantín español Coruñes acabado de formar nuevamente de cobre al mando de su capitán Clemente Reguera. Admite pasajeros y se despacha en la Casa de Comercio Francisco Ferrer y Albà, Cantón Pequeño n. ${ }^{\circ} 12$ (Boletín Oficial de la Provincia de la Coruña, Junio 1841).

Además de todas esas embarcaciones contaba nuestro personaje con los guardacostas la Golondrina y Hermosa Rita «armados y dispuestos para perseguir a los contrabandistas», así como también lanchas, minuetas y botes como el Mosquito que servían para trasladar la sardina y demás pesca salada desde los puertos cercanos (Miño, Sada y Fontán) hasta el núcleo coruñés. A este respecto, los fomentadores catalanes solían controlaban la transformación y comercialización de los productos de la mar que adquirirían a los pescadores autóctonos ${ }^{62}$. Ferrer y Albà fue uno de los principales impulsores de la lucha para establecer una sociedad industrial de protección mutua entre todos los fomentadores de Galicia a mediados de los años cuarenta. Para tal fin, fue elegido como representante de los industriales coruñeses (que tenían fábricas de pesca y salazón en este puerto y otros cercanos) en todas la Juntas que se pudieran celebrar en la provincia para constituir dicha sociedad ${ }^{63}$. Fue precisamente en este período cuando Ferrer y Albà reforzó sus actividades industriales construyendo una tercera fábrica de salazón en San Pedro de Visma (parroquia de A Coruña) sobre un terreno adquirido a Gregorio Abelenda y hermanos en $1830^{64}$.

También aprovechó nuestro protagonista toda oportunidad de formar parte de las compañías de seguros marítimos establecidas por los comerciantes más impor-

\footnotetext{
62 Normalmente trabajaban en Compañía en los tratos con los pescadores. Aparecen así referencias de un poder que dio todo el grupo de fomentadores catalanes (entre ellos Francisco Ferrer y Albà) que trabajaban en estas costas con el fin de que Pedro Martí Sanz les representara para ajustar y convenir con los pescadores de este puerto y el del Pasaje la compra de sardina que cojan en sus cedazos y demás aparejos de pesca, por tiempo, precios y condiciones convenientes en beneficio de la compañía. AHPC, Not. Manuel Antonio Lodeiro, Protocolo 8556, fols. 172-73.

${ }^{63}$ AHPC, Not. Benito María Lores, Protocolo 9160, fol. 65. «Francisco Gurrea, Francisco Pull, Geronimo Vidal, Luis Yllá y otros, fomentadores y vecinos de la Coruña dieron voto a favor de Francisco Ferrer y Albà, otro de los fomentadores, para que los represente en toda Junta que se celebre en Galicia para la creación de una sociedad de protección de todos los fomentadores del Reyno». Prueba de esta labor es el anuncio que aparece en el Boletín Oficial de la Provincia de Mayo de 1846 «Don Francisco Ferrer y Albà, domiciliado en el Cantón de Lacy n. ${ }^{\circ}$ 12, cita a los contratados para tripular el galeón y las lanchas del cedazo de la compañía de fomentadores de esta ciudad para la presente cosecha».

${ }^{64}$ AHPC, Not. Ruperto Suárez (1869), Protocolo 9726, fol. 2.040.
} 
tantes de la ciudad. Así, en 1841, aparece inscrito nuevamente en la matrícula de comercio como participante de la sociedad «Compañía de seguros marítimos denominada Integridad» que aseguraba todos los riesgos de maniobra de buques y sus cargamentos ${ }^{65}$. Posteriormente, en 1845, sería la «Compañía de Seguros Marítimos de la Coruña Herculina» el objetivo de su inversión. En particular, esta última fue una sociedad establecida por cinco años, con un fin similar a la anterior pero con un capital social muy superior; cuatro millones de reales divididos en doscientas acciones de 20.000 reales de vellón cada una y repartidas entre un total de 23 socios, cuyos nombres y apellidos coinciden en gran parte con los anteriormente mencionados ${ }^{66}$.

Además, al igual que la mayor parte de comerciantes coruñeses de la época, Francisco Ferrer y Albà aprovechó en numerosas ocasiones sus embarcaciones para ejercer la trata de negros. El comercio de mano de obra esclava en Galicia se desarrolló como una actividad alternativa al tráfico colonial tras el establecimiento del comercio directo de los europeos con las colonias españolas en América en 1797. Los comerciantes coruñeses fueron principalmente los encargados de dirigir esa actividad comercial. Una tarea que llevaron a cabo con idénticas estrategias e inversiones que las utilizadas para el tráfico de otras mercancías.

«Aunque no constituían una inversión cuantiosa o superior a la de cualquier mercancía cara y deteriorable de las muchas que se exportaban a Indias. El comercio de esclavos tenía la ventaja de asegurar una venta rápida y a precios elevados en la Habana, ventaja de la que no siempre disponían otras mercancías. Con el producto de la venta, los negreros adquirían coloniales que eran transportados y vendidos en la Coruña o reexportados a Europa» ${ }^{67}$.

En septiembre de 1817 España firmó un tratado de abolición del tráfico de esclavos con Gran Bretaña, acuerdo en el que se establecía una moratoria de tres años para que los comerciantes españoles tuvieran tiempo suficiente para reconvertir sus actividades. Cuando el 31 de diciembre de 1820 espiró el plazo concedido para la reorientación del tráfico, comenzó la extensión de la actividad de manera ilegal. Los comerciantes españoles utilizaron todo tipo de argucias para llevar esclavos a América empleando navíos de pabellones extranjeros, realizando desem-

\footnotetext{
${ }^{65}$ Esta compañía estaba dirigida por Juan Menéndez y eran socios de ella 21 individuos (entre los que está Ferrer y Albà), todos ellos matriculados en el comercio de esta ciudad. Aparecen apellidos tan conocidos en el ámbito mercantil coruñés como Galcerán, Fullós, Herce, Pull o Núñez la Barca, entre otros. AHMC, Cajas de Intendencia 1011-1012.

${ }^{66}$ ARG, Registro Mercantil y de buques (1845), n. ${ }^{\circ} 124$.

${ }^{67}$ Alonso Alvarez (1986), p. 231.
} 
barcos nocturnos... Todo ello provocó la vigilancia y persecución de los navíos negreros por parte de cruceros ingleses «que hicieron cada vez más arriesgadas las expediciones africanas, presionando fuertemente sobre los precios de los inmigrantes forzados a Cuba» ${ }^{68}$. Esta persecución no fue óbice para que los beneficios directos de la venta de esclavos se incrementaran progresivamente a lo largo de la primera mitad del siglo XIX, alcanzándose unos valores máximos en los años treinta. Es precisamente en esta década donde tenemos las principales referencias de los viajes de tráfico de esclavos realizados por las embarcaciones propiedad de Francisco Ferrer y Albà:

Muestra de los viajes realizados por embarcaciones de Francisco Ferrer y Albà con esclavos

\begin{tabular}{|clllc|}
\hline Año & Embarcación & Viaje & Bandera & Esclavos transportados \\
\hline 1826 & Dichosa & Africa-Guanimar (Cuba) & Española & 158 \\
1829 & Golondrina & Africa-Santiago de Cuba & Española & 78 \\
1831 & Coruñés & Africa-Santiago Cuba & Española & 365 \\
1838 & Dos Amigos & Africa-Cuba & Portuguesa & 316 \\
1839 & Casualidad & Africa-Guanimar (Cuba) & Portuguesa & 489 \\
1839 & Dos Amigos & Santo Tomé-Guanimar(Cuba) & Portuguesa & 413 \\
\hline
\end{tabular}

Fuente: Cortesía del prof. Alonso Alvarez. British Library, Parlamentary Papers (P. P.); 1826/XXVI; 1829/XXVI; 1831/XLVII; 1838/L; 1839/XLVIII-XLIX; 1842/XI-XII y LVIII-LIX. En 1830 los Dos amigos fue capturado por los británicos (P. P.; 1842/LXIV) y en 1835 fue capturado la Golondrina (P. P.; 1842/XLIV).

A raíz de lo visto, parece que debieron de ser años florecientes para la empresa, parte de cuyos beneficios invirtió Francisco Ferrer y Albà en la compra de numerosas propiedades (tierras, casas y almacenes) ${ }^{69}$ y en realizar mejoras en la

\footnotetext{
68 Alonso Alvarez (1994), p. 81.

${ }^{69}$ En 1822 compró una tierra en S. Lorenzo de Irijoa (Betanzos) con casa y lugar, AHPC, Not. Rafael Nogueira, Protocolo 8106, fol. 50. En el mismo año adquirió el terreno inmediato a la sala capitular del gremio del mar de la Coruña en la calle Arenal, Idem, fol. 53. En 1827 compró una casa en la calle de la Amargura número 22 a su cuñada Vicenta Sequeiros, AHPC, Not. Fernández Bó, Protocolo 7936, fol. 111. En 1831 compró una heredad en la Iglesia Vieja y arruinada de San Pedro de Visma en los extramuros de la ciudad. AHPC, Not. Pelayo Iglesias de Carvajal, Protocolo 8818, fol. 54. Entre otros muchos terrenos y sembraduras en las parroquias de San Roque, San Pedro de Visma y San Jorge de afuera. La inversión inmobiliaria constituyó una opción habitual entre los industriales y comerciantes en este período, tanto por las oportunidades que proporcionaba el proceso desamortizador como porque estas adquisiciones eran consideradas, en esos tiempos, las más seguras y de menor riesgo.
} 
sede central de sus negocios y, a la vez, hogar de la familia ${ }^{70}$. Junto con toda esta frenética actividad empresarial Francisco Ferrer y Albà desarrolló una activa vida política y social. El 19 de abril de 1820 se convirtió en el noveno regidor -de los diez existentes- en el Ayuntamiento de la ciudad. Formaba parte un gobierno municipal liberal, compuesto fundamentalmente por burgueses y comerciantes que en el acto de investidura «juraron guardar y hacer guardar y cumplir la Constitución» ${ }^{71}$.

En realidad entre 1812-14 y 1820-23, los burgueses y comerciantes controlaron plenamente el Ayuntamiento con el espíritu de liberalizar la administración local. Esta lucha por la causa liberal constituyó el principal objetivo de la gerencia municipal durante el Trienio. En un contexto de enormes dificultades políticas y de graves apuros para la Hacienda gubernamental cualquier otra iniciativa quedaba relegada a un segundo plano. El final del breve período liberal provocó un cambio radical en los apellidos que protagonizaban la vida política local y, con ello, la desaparición de nuestro protagonista de las tareas consistoriales. En 1834, ya fallecido Fernando VII, de nuevo reaparece Ferrer y Albà en la política municipal como alcalde interino. Un año más tarde, en 1835, se convirtió en primer regidor del cabildo y, en octubre de 1836, juró cargo como segundo alcalde ${ }^{72}$. Debido a la normativa aprobada por Real Orden de 17 de febrero de 1838 que expresaba la obligatoriedad de renovar anualmente los señores alcaldes y la mitad de regidores tuvo que dejar el cargo. Este paréntesis en su actividad consistorial fue aprovechado por Ferrer y Albà para convertirse en vicepresidente de la Junta de Comercio de la ciudad:

«En seguida se dio cuenta de un oficio del señor jefe politico de esta provincia fecha 10 del citado mes de diciembre en que traslada la Real Orden de 29 de Noviembre pasado por la cual se ha designado S. M. la Reyna Governadora nombrar Vicepresidente de esta Junta de Comercio al señor D. Francisco Ferrer y Albà sustituyendo a D. Martín de Torres Moreno» ${ }^{73}$.

\footnotetext{
${ }^{70}$ En el Padrón de 1836 (el primero existente en A Coruña), aparece en el barrio 5. ${ }^{\circ}$, Cantón Pequeño, casa n. ${ }^{\circ} 12$, con dos habitaciones y 11 vecinos; Francisco Ferrer y Albà, casado con María Ros de 58 y 34 años respectivamente. Él figura como comerciante y su mujer gobierna la casa. Tienen ocho hijos (todos solteros); Fermina (13), Pedro (12), Romana (11), Francisca (9), Elías (7), Damiana (6), Juan (5) y Ramona (4). Además, consta también una sirvienta, Manuela Gómez. AHMC. Padrones, 1836, Barrio 5. ${ }^{\circ}$

${ }^{71}$ AHMC, Actas Municipales, 1820. Aparecen como miembros del Consistorio en ese año apellidos tan representativos en el liberalismo coruñés como Romeu o Galcerán que, por otra parte, eran también destacados comerciantes de la Plaza y tenían origen catalán.

${ }^{72}$ AHMC, Actas Municipales, $1820-23$ y $1834-38$.

${ }^{73}$ ARG, Actas del Libro del Tribunal de Comercio, 1836-1851.
} 
No tardaría mucho en retomar su actividad municipal. En plena regencia de Espartero y con los progresistas en el poder, en la Sesión Plenaria del Ayuntamiento de 4 de enero de 1842 se convirtió Francisco Ferrer y Albà en el alcalde de la ciudad $^{74}$. Una alcaldía con sede, desde el 13 de diciembre de 1838, en el antiguo convento de San Agustín (que recientemente había sido desamortizado por Mendizábal) extramuros del primitivo núcleo de población coruñés ${ }^{75}$. Sería ésta la culminación de su carrera política y su máximo pedestal en el escalafón social. A finales de la década de los cuarenta Francisco Ferrer y Albà y sus hijos mayores, Francisco y José realizaron la liquidación de su sociedad mercantil para solemnizar escritura pública y establecer sus bases de manera legal. En este ajuste de cuentas previo a la formalización jurídica expresaban;

«Que habiendo determinado hace algunos meses de mutua conformidad la liquidacion de dicha sociedad se ocuparon de ella y practicaron el correspondiente balance fijado a 31 de enero del mismo, el cual ha sido minuciosamente examinado y aprovado por los tres socios de la compañía y del que consta que la casa de comercio en que los tres interesan cuenta con un capital liquido de 1.446 .016 reales y $1 \mathrm{~m}$. En metalico, creditos, buques, fincas, efectos y otras acciones, habiendo fijado de comun acuerdo los valores de todo entre los socios, como consta por menester en todas las cuentas, relaciones, notas y mas documentos que acompañan al referido balance, asi como tambien se expresa en el mismo la parte de realizable y realizada del capital asi como tambien la que presenta mas tardia realizacion. Por el mismo valance se observa corresponder al Francisco mayor por el capital que aporto a la compañía la mitad de las utilidades habidas desde 1829 y hasta la fecha del balance de cantidad 381.917 reales 14 maravedies en capital realizable y 517.363 reales y 31 maravedies en valores de tardia realizacion y a los dos mencionados hijos por iguales conceptos y a dividir por la mitad la cantidad de $381.917,, 14$ de capital realizable y $244.817,29$ en valores de tardia realizacion. Los tres socios aprueban el balance y tambien estan dispuestos a continuar la sociedad con los referidos capitales. Como desean seguir en sociedad no necesitan hacer division y sorteo» ${ }^{76}$.

Cumpliendo su deseo otorgaron establecer en 18 de febrero de 1849 una escritura $^{77}$ de sociedad con duración de cinco años y razón social Francisco Ferrer y Albà. Las labores de administración y gestión estarían a cargo de los tres socios

${ }^{74}$ AHMC, Actas Municipales, Caja 102.

${ }^{75}$ Fernández (1997), p. 24. El Ayuntamiento de Coruña tuvo un emplazamiento errante hasta que a principios del siglo XX se construyó el actual edificio en la Plaza de María Pita.

76 AHPC, Not. Ruperto Suárez (1847), Protocolo 9691, fol. 413.

77 AHPC, Not. Manuel Lodeiro (1849), Protocolo 8571, fol. 84. Donde se establecen las bases de la sociedad en escritura pública con 10 puntos en los que se establecen las características descritas en el texto. Es un contrato firmado por los tres socios que se comprometen a respetarlo. 
indistintamente, estableciendo además la prohibición de negocios de ninguna clase por cuenta propia. Asimismo fijaron una manutención anual para gastos particulares de 1.000 reales de vellón para cada uno de ellos, independientemente de que las ganancias se adjudicaran en un $45 \%$ al padre y otra igual parte a repartir entre sus dos hijos mayores. El 10\% restante se les asignaría a Elías y Manuel Ferrer y Ros, hijos del segundo matrimonio de Francisco que, sin parte en la dirección, auxiliaban a la compañía con su trabajo. A todo ello «se someten sus personas y todos sus bienes ante el Tribunal de Comercio», se entiende por tanto que la sociedad tenía carácter colectivo.

\section{EL OCASO ECONÓMICO DE LA EMPRESA FAMILIAR Y EL DECLIVE SOCIAL DE LA ESTIRPE EN EL ECUADOR DEL SIGLO XIX}

El final de la década de los cuarenta del siglo XIX sumergió a Europa en un ciclo recesivo que tocó fondo en la crisis de 1848. La difícil situación afectó también a la economía española y Galicia no fue una excepción.

«Esto explica la serie de quiebras que hemos localizado en la burguesía compostelana... con la suspensión de pagos del grupo empresarial más poderoso de Galicia, la firma 'Perez Santamarina' que arrastró consigo a una constelación de pequeñas y medianas empresas... En 1852 suspende pagos la firma 'Abella y Cía' en Coruña y entra en crisis en la misma ciudad la firma Brañas...» ${ }^{78}$.

La burguesía comercial e industrial fue una de las principales afectadas en la crisis. En ese clima de inestabilidad, a mediados del siglo XIX, comienzan los problemas para el apellido Ferrer y Albà. En ese momento la Casa de Comercio Francisco Ferrer y Albà actuaba como representante en la ciudad y participaba con una octava parte del capital en la empresa de diligencias «Viuda del Poniente y resto de la Navarra y Gallega» que comunicaba Madrid con Galicia y Asturias ${ }^{79}$. En calidad de representantes de esta compañía, los tres socios habían negociado abundantes letras con numerosos comerciantes de la ciudad. Las dificultades por las que pasó esta empresa de diligencias a principios de los cincuenta provocaron que una gran parte de estas letras negociadas vinieran protestadas y acompañadas de las respectivas cuentas de resaca desde Madrid. La sociedad Ferrer y Albá se encontró así,

\footnotetext{
${ }^{78}$ Barreiro (1996), pp. 440-444.

${ }^{79}$ Empresa de origen navarro pero a cargo de una dirección mixta que tenía su sede en Madrid. AHPC, Not. Manuel Lodeiro (1852), Protocolo 8575, fol. 258. Por su participación y su labor de representación la sociedad cobraba un porcentaje mensual de los beneficios del negocio.
} 
a finales de 1851, con una gran cantidad de letras a las que no podía hacer frente «sin dejar desatendidos sus negocios» ${ }^{80}$. Las letras adeudadas sumaban más de 300.000 reales de vellón y se distribuían entre distintos comerciantes de la plaza de la siguiente forma (en reales de vellón); Juan Menéndez (154.000); Francisco Ortega (30.000); Diego M. ${ }^{a}$ Bolivar (40.000); Bruno Herce (21.704); Bernardo Mariach (20.000); Leoncio de Aspe (20.000); Bartolomé de Casas Díez (5.000); Carricarte y Cía (8.000).

Dada la gravedad de la situación Ferrer y Albà logró llegar a un acuerdo con sus acreedores en febrero de 1852. En dicho arreglo se establecía el pago de 1/3 de la deuda al contado y el resto (2/3) en plazos de 6, 8, 10 y 12 meses, fijando un tipo de interés del $6 \%$ anual. A la garantía del pago y en nombre de la sociedad hipotecaron los bienes de la Compañía señalando especialmente los siguientes; Almacén y fábrica de salazón de la Palloza, $n .^{\circ} 15$; Casa de la calle de la Amargura, n. ${ }^{\circ} 22$; Almacenes n. ${ }^{\circ} 20$ A y 23 B de la calle del Orzan; Almacén, casa y fábrica de salazón de San Pedro de Visma y el resto de bienes situados en la misma parroquia. Los esfuerzos por remontar esta situación se hicieron inútiles cuando a lo largo de los siguientes meses el goteo de nuevas letras y pagarés devueltos continuóo ${ }^{81}$. La disculpa que manifestaba Francisco Ferrer y Albà cuando se le presentaba el notario en su domicilio para exigir el pago de las deudas era siempre la misma;

«no pago porque desde la llegada del Correo de Madrid último se me han presentado en el y en los anteriores letras giradas por el que contesta al cargo del librador Jose Mosquera, Director de la Empresa Navarra de Diligencias, que fueron protestadas por falta de pago. Cuyas letras no tenían objeto que el de hacer fondos para pagar las giradas, toda vez que en mi poder no existen otros de mi pertenencia».

En el mes de abril de 1852, para mayor gravedad, hubo de hacer frente a un pleito con el Ministerio Fiscal que le reclamaba el pago de dos nuevas letras giradas en Madrid a cargo de Francisco Ferrer y Albà por valor de 22.000 reales. El tribunal falló en su contra y tuvo que hacer frente al pago de las deudas, a las cuentas de resaca y a las costas del juicio ${ }^{82}$. La situación era cada vez más crítica y estalló a principios de junio cuando, en plenas dificultades, falleció de muerte natural («consumición», según consta como causa de muerte en la partida de defunción) el

${ }^{80}$ AHPC, Not. Ruperto Suárez (1852), Protocolo 9696, fol. 1113.

81 Únicamente en el Protocolo 8575 del notario Manuel Lodeiro en los meses comprendidos entre Febrero y Junio de 1851 se sucedieron seis nuevos protestos de letras y pagarés a cargo de Francisco Ferrer y Albà por valor superior a 50.000 reales de vellón. AHPC, Not. Manuel Lodeiro (1852), Protocolo 8575, fols. 17, 18, 45, 212, 213, 216.

${ }^{82}$ ARG, Figueroa, Particulares, leg. 4799, n. 70. 
patriarca de la familia Francisco Ferrer y Albà de 75 años, quien fue enterrado en la parroquia de San Jorge ${ }^{83}$. Días más tarde los dos hijos mayores del difunto preparaban los papeles para declararse en quiebra;

«Francisco Ferrer y Albà dice estar liquidando la Casa por fallecimiento del padre $y$, después de haber tenido una conferencia con los hermanos del segundo matrimonio en la que quedaron conformes, se hallo sorprendido y atropellado por el Juzgado de Primera Instancia a petición de aquellos, llegando al extremo de haberle sellado el escritorio y almacenes en virtud de lo cual no tubo otro recurso que presentarse en quiebra ante el Tribunal de Comercio de esta Plaza para evitar tales atropellamientos» ${ }^{84}$.

Efectivamente, se presentaba la memoria de la liquidación y se publicaba la quiebra de la Casa de Comercio en el Boletín Oficial de la Provincia en 5 de julio de $1851^{85}$ :

«Don Domingo Conde, consul segundo de esta plaza.

Hago notorio: Que dicho Tribunal por auto de 24 de Junio último, declaró en estado de quiebra la sociedad conocida bajo la razon de Francisco Ferrer y Albà, de este comercio, a solicitud de los socios liquidatarios Don Francisco y Don José Ferrer y Albà, de la que me nombro Juez Comisario. Por tanto prevengo que no se haga entrega de pago alguno a los sobredichos y sí al Depositario Sebastian Wais de este Comercio; en inteligencia de que el que lo verificare a aquellos, no quedara descargado. Igualmente mando que los que tengan pertenencias de los quebrados las manifiesten por nota ante mi. Y respecto (a que) no acompañaron a su memoria el balance general que previene el articulo 1018 del Codigo el tribunal conforme al 1060, les señalo ocho dias de termino para formalizarlo reservandose en su visita la convocatoria de los acreedores a la primera Junta General. Coruña, Julio 5 de 1852, anotado, n. ${ }^{\circ} 552 »$.

En los siguientes meses se presentaron a la quiebra por medio de sus apoderados numerosos acreedores que trataban de recuperar sus deudas. Francisco y José Ferrer y Albà delegaron su representación en la quiebra ante el Prior del Tribunal de Comercio en la persona de Manuel de Torres, a quien dieron «poder total para su defensa en tan desdichado pasatiempo» ${ }^{86}$. Los hijos del segundo matrimonio

\footnotetext{
${ }^{83}$ AHMC, Libro de difuntos de la parroquia de San Jorge 1852, número 373. Francisco Ferrer y Albà otorgó su último testamento en 1845 ante el notario Agustín Gómez Armesto. Desgraciadamente los fondos de este notario están muy deteriorados (son prácticamente ilegibles) y el año 1845 se encuentra desaparecido del Archivo de Protocolos Notariales. De todas formas esta última voluntad quedó sin efecto por los acontecimientos sucedidos después del fallecimiento.

${ }^{84}$ AHPC, Not. Manuel Lodeiro (1852), Protocolo 8575, fol. 213.

${ }^{85}$ Boletín Oficial de la Provincia de la Coruña (1852), lunes 5 de Julio, n. 78.

${ }^{86}$ AHPC, Not. Manuel Lodeiro (1852), Protocolo 8575, fol. 229.
} 
comparecieron también en la causa y dado que, todos ellos excepto Pedro eran menores de edad, el Juzgado de primera instancia nombró un curador para la defensa de sus intereses. En la demanda común que presentaron manifestaban el derecho que tenían como herederos de María Ros (su madre) a recibir la parte correspondiente de la herencia. Por este motivo solicitaron la división y partija del patrimonio de su difunto padre ya que, a su juicio, los bienes de la legítima materna no debían de responder ante la quiebra. A todas estas demandas se emitió sentencia en junio de 1853. En el dictamen se reconocían los derechos de los hijos del primer y segundo matrimonio y por medio de la intervención de peritos se hicieron partijas adjudicando a cada interesado el haber que pudiera corresponderle.

Se estimó que el capital y parte del ganancial de María Ros ascendía a 330.499 reales de vellón y 9 maravedíes. Por este motivo se entregaron a Pedro Ferrer y sus hermanos menores (hijos del segundo matrimonio); dinero en metálico por valor de 31.498 reales de vellón y 17 maravedíes, documentos de crédito por valor de 172.492 reales de vellón y 17 maravedíes y, para completar el resto, se señalaron varias fincas del patrimonio paterno que se liquidarían en pública subasta en beneficio de los mismos. Simultáneamente a estos pleitos particulares de partijas, en el Tribunal de Comercio se gestionaba la quiebra de la sociedad. La primera decisión fue el nombramiento de un síndico en la Junta de acreedores. La elección recayó en la persona de Sebastián Wais, quien sería el encargado de sacar el mayor partido posible a los bienes de la sociedad quebrada. De este modo Wais tramitó el alquiler de los almacenes y las fábricas, liquidó las participaciones en distintas sociedades y empresas de la disuelta compañía y vendió barcos, casas y fincas pertenecientes al patrimonio de los tres socios. Lo recibido de todas estas gestiones se utilizó para redimir débitos.

Una vez realizados los trámites oportunos y celebradas todas las vistas, se procedió finalmente a la subasta pública de los bienes pendientes de liquidar. En esta venta pública, anunciada por edicto en el Boletín Oficial de la Provincia en abril de $1859^{87}$, sólo compareció el único socio superviviente de la Casa quebrada, José Ferrer y Albà. Su hermano Francisco había fallecido poco después del anuncio de la quiebra, el 28 de septiembre de 1852, a la edad de 46 años $^{88}$. El día 9 de mayo de 1859 a las doce de la mañana en el despacho del escribano Manuel de la Rosa se vendieron en almoneda más de treinta piezas de tierra, sembraduras y montes, tres casas terreñas, hornos y lugares, las fábricas de salazón y las fincas urbanas

${ }^{87}$ Boletín Oficial de la Provincia, 1859.

${ }^{88}$ AHMC, Libro de defunciones 1852, n. ${ }^{\circ}$ 570. Muerte de Francisco Ferrer y Albà a la edad de 46 años a causa de una dolencia crónica de estómago e hígado. No dejó testamento porque sus bienes tenían que responder de la quiebra de la Casa de Comercio. 
pertenecientes a la desaparecida sociedad. Todos estos bienes estaban situados en la ciudad de A Coruña y sus alrededores. Simbólica fue, sin duda, la subasta pública de la Casa Grande situada en el Cantón de Laci (antes Cantón pequeño) número 12 que tuvo como mejor postor a Francisco Otero y Mirando quien ofreció 131.000 reales. El dinero recibido en estas ventas fue repartido equitativamente entre los acreedores de la firma.

Pedro Ferrer, el hijo mayor del segundo matrimonio, teniente coronel de artillería destinado en el Ministerio de Guerra en Madrid, recuperó en la subasta, junto a sus hermanos pequeños, las fábricas de salazón ${ }^{89}$. Sus intentos por continuar con la industria familiar fueron vanos porque dichas fábricas tuvieron que ser vendidas por los hermanos Ferrer a finales de los años sesenta a un precio muy bajo «por el estado de deterioro y ruina en la que se encuentran tanto los edificios como las embarcaciones y aparejos trahiñas» ${ }^{90}$.

El apellido Ferrer y Albà desapareció de las elites comerciales y políticas de la ciudad. A diferencia de otras sagas de origen catalán que, aún en el siglo XX, siguieron formando parte activa de la vida económica de la urbe, los Ferrer y Albà no pudieron superar el ecuador decimonónico ${ }^{91}$. Representaba el final simbólico de una de las muchas sagas de origen catalán que, en tiempos del Antiguo Régimen, imaginaron Galicia como el escenario ideal para poder desarrollar sus actividades mercantiles. Para los protagonistas de estas páginas lo fue durante casi un siglo.

\section{Fuentes}

ARG: Archivo Histórico del Reino de Galicia

AHPC: Archivo Histórico de Protocolos Notariales de A Coruña

AHMC: Archivo Histórico Municipal de A Coruña

BC: Biblioteca del Real Consulado de A Coruña

Boletín Oficial de la Provincia de A Coruña 1835-1840; 1850-1854; 1859

\footnotetext{
${ }^{89}$ AHPC, Not. Manuel de la Rosa (1859), Protocolo 9942, fols. 175 y 197.

${ }^{90}$ AHPC, Not. Benito M. a Lores (1864), Protocolo 9180, fols 169 y ss.

${ }^{91}$ Los hijos supervivientes del segundo matrimonio en los años sesenta son; Pedro Ferrer, militar de profesión, que en este período estaba destinado en la isla de Santo Domingo; Romana, casada con el capitán del batallón de provinciales Vicente Nuñez de Noboa y residentes en Orense; Francisca y Damiana que quedarían solteras y Elías, el único dedicado a la actividad comercial pero de manera mucho más modesta que las generaciones precedentes (como dependiente de otro establecimiento). De José Ferrer y Albà, único hijo superviviente del primer matrimonio, no se han encontrado referencias. AHPC, Not. Benito M. ${ }^{a}$ Lores (1864), Protocolo 9180, fol. 169 y Ruperto Suárez (1865), Protocolo 9709, fol. 363.
} 


\section{BIBLIOGRAFÍA}

Almanak Mercantil, o guía de comerciantes, Madrid 1795-1807.

ALONSO ALVAREZ, L. (1976): Industrialización y conflictos sociales en la Galicia del Antiguo Régimen, 1750-1830, Ed. Akal, Madrid.

ALONSO ALVAREZ, L. (1986): «Comercio colonial y crisis del Antiguo Régimen en Galicia (17781818)», Ed. Xunta de Galicia.

ALONSO ALVAREZ, L. (1994): «Comercio exterior y formación de capital financiero: el tráfico de negros hispano-cubano, 1821-1868», Anuario de Estudios Americanos, tomo LI, n. ${ }^{\circ} 2$, pp. 75-92.

ALONSO ALVAREZ, L. (1996): «Emigrantes catalanes en Galicia, 1760-1832», en M. T. Pérez Picazo (eds.), «La penetració comercial catalana a l’Espanya interior en el segle XVIII», pp. 97-107.

ARCHIVO HISTÓRICO DE PROTOCOLOS DEL ILUSTRE COLEGIO NOTARIAL DE LA CORUÑA: Inventario de Protocolos Notariales La Coruña: 1563-1894.

BARREIRO, X. R. (1982): Liberales y absolutistas en Galicia, Ed. Xerais, Santiago de Compostela.

BARREIRO, X. R. (1996): Historia de la ciudad de A Coruña, La Coruña, La Voz de Galicia.

BARTHÈLEMY, R. G. (1995): El Marquesito Juan Díaz de Porlier General que fue de los Ejércitos Nacionales... (1788-1815), Universidad de Santiago de Compostela, Vol. I y II.

BEIRAS, X. M. (1995): O atraso económico da Galiza, Ed. Laiovento, Santiago de Compostela.

CARMONA BADÍA, J. (1990): El atraso industrial de Galicia, Ariel, Barcelona.

CARRE ALDAO, E. (1915): «La causa Porlier», Boletín de la Real Academia Gallega, X, N. ${ }^{\circ}$ 98, pp. 25-31.

CORNIDE, J. (1774): Memoria sobre la pesca de la sardina en las costas de Galicia, Madrid.

FERNÁNDEZ FERNÁNDEZ, X. (1997): Historia del Ayuntamiento de La Coruña, Ed. Vía Láctea, Coruña.

FONTANA, J. (1977): La revolución liberal (Política y Hacienda, 1833-1845), Madrid.

FONTANA, J. (1981): «La financiación de la guerra de la Independencia», Hacienda Pública, 69, pp. 209-217.

GARCÍA BARROS, J. (1970): Medio siglo de vida coruñesa, 1834-1886, La Coruña.

GONZÁLEZ LÓPEZ, E. (1987): «La Coruña puerto y Puerta de la Ilustración», Ed. Diputación de A Coruña.

LINDOSO TATO, E. (1996): Empresas y empresarios en La Coruña, 1830-1914, Tesis de licenciatura inédita, Universidade da Coruña.

LINDOSO TATO, E. (1999): Empresas y empresarios en La Coruña, 1830-1914, Fundación Empresa Pública, Madrid.

LÓPEZ CAPONT, F. (1998): El desarrollo industrial pesquero en el siglo XVIII. Los salazoneros catalanes llegan a Galicia. Fundación Barrié de la Maza, A Coruña.

MEIJIDE PARDO, A. (1982): Escritos e autores na Galicia da Ilustración, Fundación Barrié de la Maza Conde de Fenosa, A Coruña. 
MEIJIDE PARDO, A. (1984): «Estirpes catalanas en la Coruña; J. Galcerán, hombre de negocios y político liberal (1765-1837)», en Revista Pedralbes, vol. 4, pp. 7-30.

MEIJIDE PARDO, A. (1993): «Aspectos de la vida económica de Pontedeume en el siglo XVIII», en Anuario Brigantino, n. ${ }^{\circ}$ 16, pp. 61-71.

MEIJIDE PARDO, A. (1995): «La economía marítima de Sada y Fontán en la época precapitalista: Los salazoneros catalanes.», Revista Anuario Brigantino, n. ${ }^{\circ} 18$, pp. 91-104.

MEIJIDE PARDO, A. (1997): Temas y personajes de la historia coruñesa contemporánea, Diputación de A Coruña, A Coruña.

RODRÍGUEZ VARELA, E. (1977): «El Real Consulado de Comercio de la Coruña y la apertura del comercio indiano», en Eiras Roel, A. y otros, Las fuentes y los métodos. 15 trabajos de historia cuantitativa serial de Galicia, Santiago de Compostela, pp. 307-321.

ROMANÍ, A (1997): Unha industria salgadeira catalana en Galicia, Xunta de Galicia Santiago de Compostela.

SÁNCHEZ RODRÍGUEZ DE CASTRO, M. C. (1992): El Real Consulado de La Coruña: Impulsor de la Ilustración (1785-1833), A Coruña.

TETTAMANCY GASTÓN, F (1900): Apuntes para la Historia Comercial de La Coruña, Edición Facsimilar (1994), Ayuntamiento de La Coruña.

TORRAS, J. (1987): «L'economia catalana abans del 1800. Un esquema», en Historia Económica de la Catalunya Contemporánea, vol. 1, Eds. 62, Barcelona.

TORRAS, J. (1996): «La penetració comercial catalana a 1'Espanya interior en el segle XVIII. Una proposta d'explicació» en M. T. Pérez Picazo (eds.), La penetració comercial catalana a l’Espanya interior en el segle XVIII, pp. 27-30.

VEDIA Y GOSSENS, E. (1845): Historia y descripción de la ciudad de La Coruña. Editado por el Instituto de Estudios Coruñeses «José Cornide» (1975), A Coruña.

VV.AA (1994): Antiguo Régimen y liberalismo. Homenaje a Miguel Artola, Ed. Alianza, Madrid.

VV.AA (1995): Historia de La Coruña, Ed. Vía Láctea, La Coruña. 
